\title{
Effect of Inadequate lodine Status on Academic Performance of Secondary School Girls in Sokoto State, Nigeria
}

\section{${ }^{*}$ Umar Al, ${ }^{2}$ Umar RA, ${ }^{2}$ Wasagu RSU and ${ }^{3}$ Oche MO}

\author{
${ }^{1}$ Department of Biochemistry, Sokoto State University, Sokoto, Nigeria. \\ 2Department of Biochemistry, Usmanu Danfodiyo University, Sokoto, Nigeria. \\ ${ }^{3}$ Department of Community Health, Usmanu Danfodiyo University Teaching Hospital, Sokoto Nigeria.
}

\section{ARTICLE INFO}

Article No.: 122117184

Submitted: $21 / 12 / 2017$

Accepted: 06/01/2018

Published: 16/01/2018

${ }^{*}$ Corresponding Author

E-mail: mamunetdaji@

gmail.com

Phone: +2348065310438

Keywords: lodine Status, Female Secondary School Students, Academic Performance and Sokotochildren who would be enrolled in schools.
DOI: 10.15580/GJEPH.2018.1.122117184

Umar A.l.

\section{ABSTRACT}

lodine is an indispensable micronutrient essential for the normal, physical, mental development, and well-being of all humans. Although Sokoto State has long been considered iodine sufficient, increasing evidence suggests that it might now be mildly to moderately iodine deficient. The study assessed whether mild to moderate iodine deficiency in adolescent's girls was associated with an adverse effect on academic performance. Systematic random sampling study was conducted among public secondary schools of the three zones of Sokoto State, 248 girls aged $14-17$ were recruited. Performance in English and Mathematics was assessed using quasi experimental method. Validated pre-test and post-test questionnaires were used to assess subject's demographical data. Interval plot was used for mean scores in performance of English and Mathematics of the study subjects, column charts was used for comparing grades of performance in English and Mathematics of the subjects in the zones. Result in means scores showed 54.4 in SCZ subjects and 54.1 in SWZ subjects compared to 38.5 in SEZ subjects. Grades of Performance in English and Mathematics showed $28.9 \%$ subjects in SCZ, $32.9 \%$ subjects in SWZ compared to $41.7 \%$ subjects in SEZ, scoring below satisfactory level ranging from fair and poor performance. Inadequate iodine level is seen to be associated with decrease in academic performance of the study subjects. Adequate iodine intake should continue to be encouraged in the general population more especially in the secondary schools girls, most of whom are at the verge of becoming mothers of State. 


\section{INTRODUCTION}

The World Health Organization (WHO) considers iodine deficiency to be "the single most significant avoidable cause of brain damage" globally (WHO, UNICEF and ICCIDD, 2007). Although iodine deficiency is often thought to be a problem of developing countries, African countries are not exempted (Anderson et al., 2012). Indeed, concern is emerging that iodine deficiency might be extensive in some part of far northern Nigerian States. This concern is based on recent results of some northern state study of adolescent school girls and pregnant women, which showed moderate to mild iodine deficiency in most of the zones of northern state of Nigeria

lodine deficiency was common in the Nigerian States until the 1990s, even though, an iodised-salt programme was introduced to eradicate the deficiency, absence of monitoring and evaluation was partial because Nigeria was declared successful in universal salt iodization programme in 2005, this was the result of external assessment of Nigeria's lodine Deficiency Disorders/Universal Salt lodization (IDD/USI) programme by the Global lodine Network, in December 2005. Nigeria's achievement of USI was globally recognized and acknowledged in December 2005, the first African country to receive such certification (IDD Newsletter, 2010) therefore, the stake holders of Nigeria's IDD/USI programme assumed to have been succeeded.

lodine deficiency has widespread implications because iodine is a key component of the thyroid hormones, which are crucial for brain and neurological development, particularly during gestation (Zimmermann, 2009). Although severe deficiency in pregnancy is well known to result in adverse childhood outcomes, such as cretinism and mental retardation, (Zimmermann, 2009) less is known about the effects of mild-to-moderate deficiency. (Zimmermann, 2007)

In humans, there is reduced school performance in children, which later leads to reduced economic productivity and quality of life in adulthood (Bleichrodt and Born, 1994; Hetzel, 2005). In Nigeria, there have been several reports of poor performance in end of secondary school examinations such as National Examination Council (NECO), National Business and Technical Education Board (NABTEB) and West African Examination Council (WAEC) (Olatunde, 2012 and Salako et al., 2017). This portends negative effects on the socioeconomic development of the country. Measures should be taken to arrest the trends. Information is therefore required on current iodine status and academic performance for planning and interventions. Currently, this information is lacking.

\section{MATERIALS AND METHODS}

Quasi experimental design was adopted among 248 female secondary school students in the zones of Sokoto State, Nigeria (having Mild to moderate iodine deficiency, with normal levels of serum T3, T4 and TSH levels) from February to July 2015. The age bracket of the study subjects were 14 - 17years, subjects with pregnancy, thyroid disease or medication containing iodine are excluded. Consent was provided for subjects' willingness to participate, pre-test and post-test questionnaires were administered to collect information on socio demographic data of study subjects. Ethical approval was obtained from research and Ethics Committee of Sokoto State Ministry of Health. Permission was granted by the Ministry of Education and Ministry of Science and Technology. A pilot study was carried out before the main study to have a tryout of the instruments and to determine their psychometric properties. Fifty Multiple Choice item tests with 4 options were developed which attracted 50 marks. The students were intensively taught and examined at three different stages for 4 weeks using Instructional Rubrics in English and Mathematics. The scoring of the instrument was done by peer, self and teacher, and 4, 3, 2 and 1 were assign for positive statements and the responses are Strongly Agreed (SA), Agreed (A), Disagreed (D) and Strongly Disagreed (SD). The points were awarded in the reverse order for the negative statements. The addition of the direct and reverse will give overall scores. The maximum overall score is 100 , while the minimum overall score is 40 (Asuai and Adeleye, 2013; White and Sabarwal, 2014). The student scores for each of the self, peer and teacher's assessment were compared for significant relationship using Pearson Product Moment Correlation statistics to estimate the test-retest reliability coefficient.

Data and information of the study subjects obtained from questionnaires and simple spreadsheet were coded and analysed into frequencies and percentage, using Excel (Microsoft, Seattle, 2003). Statistical Package for Social Science (SPSS) Version 2.2 was used for Pearson's correlation test to determine the relationship between Urinary lodine Excretion, T3, T4, TSH and Performance in Mathematics and English. Results were expressed as means \pm SD. Significant level was set at $P<0.05$.

\section{RESULTS}

Mean scores of study subjects in English is presented in figure 1. The study observed mean scores of 54.4 in SCZ subjects and 54.1 in SWZ subjects compared to 38.5 means scores in SEZ subjects. 


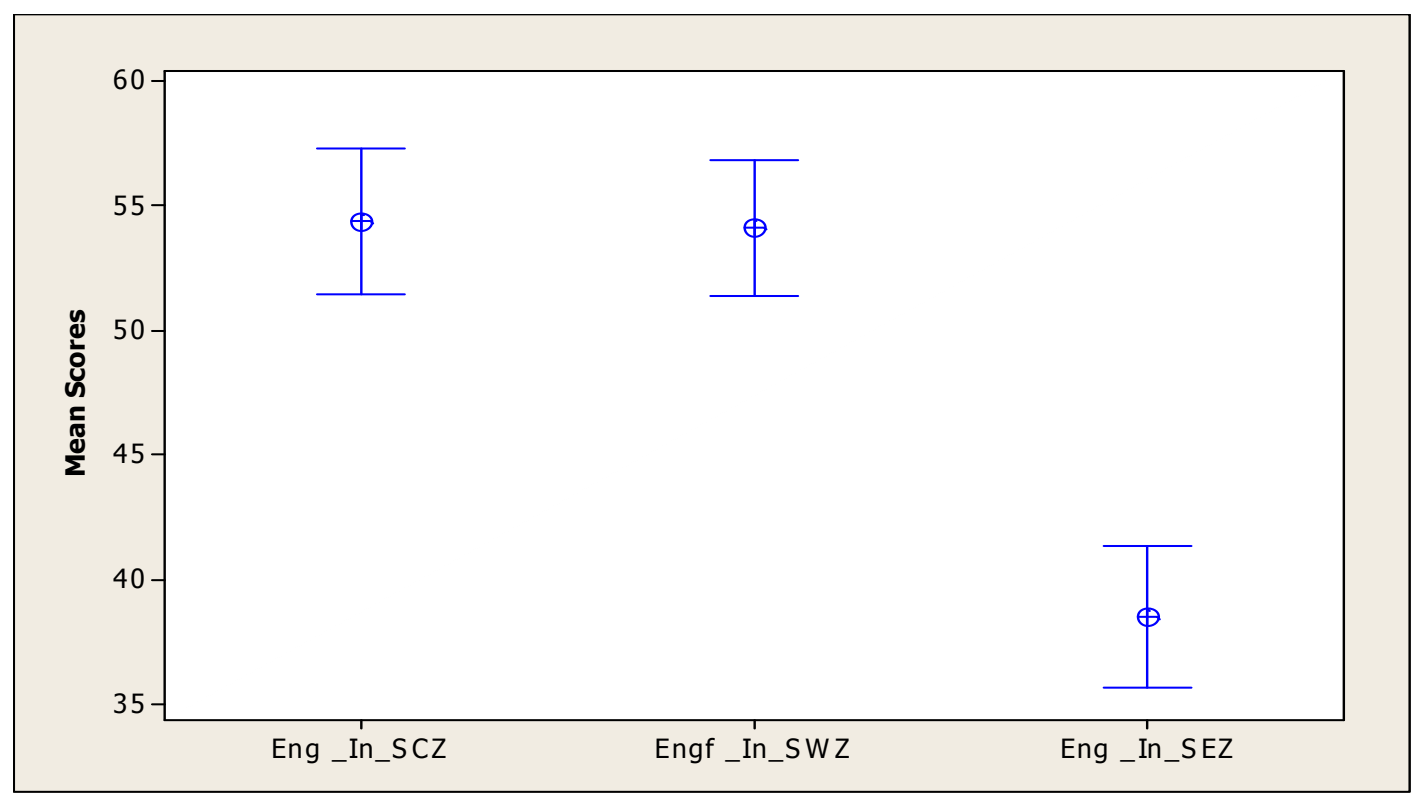

Figure 1 Mean Scores of Performance in English study subjects in the three zones of Sokoto State

The result of grades in performance of English by study subjects is presented in figure 2: Performance in English showed $28.9 \%$ subjects in SCZ, $32.9 \%$ subjects in SWZ compared to $41.7 \%$ subjects in SEZ scoring below satisfactory level ranging from fair and poor performance. Satisfactory performance was showed in $48.2 \%$ subjects of SCZ, $46.8 \%$ subjects in SWZ compared to $45.2 \%$ subjects in SEZ. The study also observed good performance in $14.5 \%$ SCZ subjects, $12.7 \%$ SWZ subjects compared to $10.7 \%$ subjects. Eight point four percent subjects in SCZ, $7.6 \%$ subjects in SWZ compared to $4.8 \%$ subjects in SEZ had an excellent performance in English.

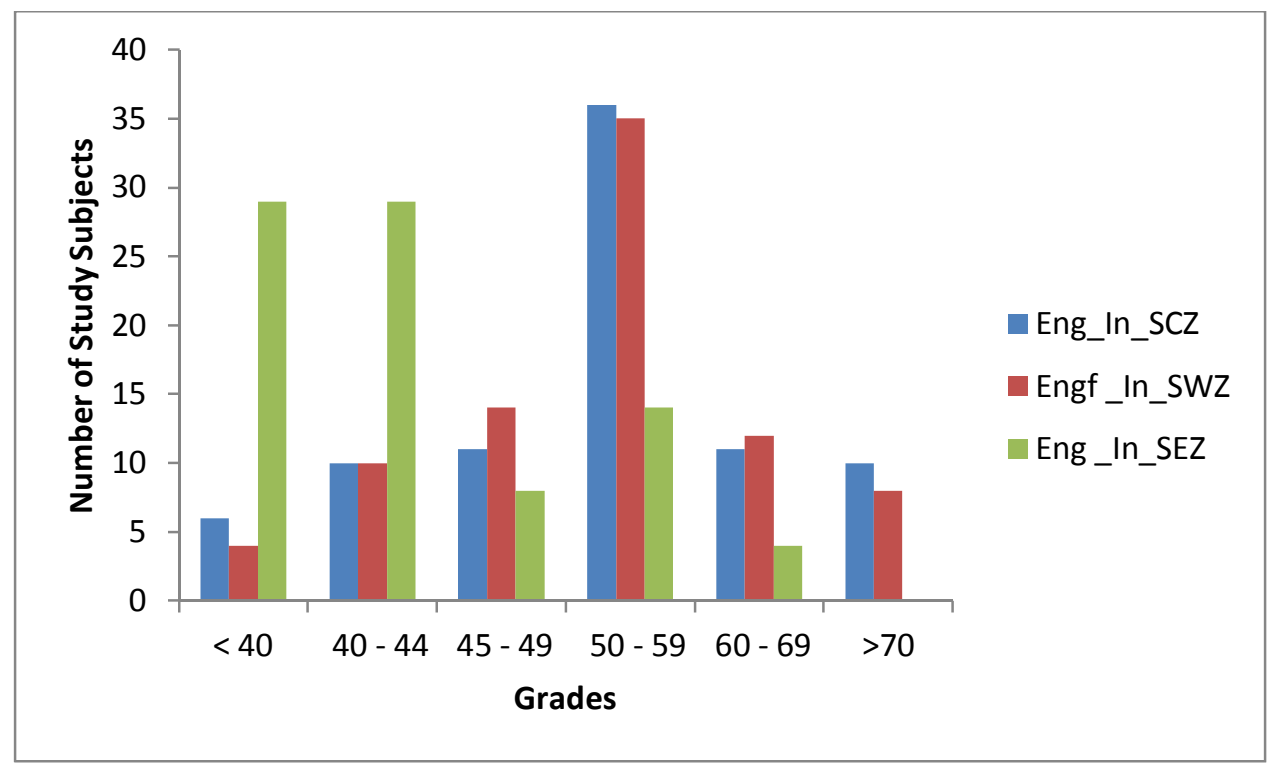

Figure 2: Grades of performance in English by study subjects in the zones of Sokoto State

Mean scores of study subjects in English is presented in figure 3. There was a mean score of 53.4 in SCZ subjects and 54.9 in SWZ subjects compared to 38.6 means scores in SEZ subjects 


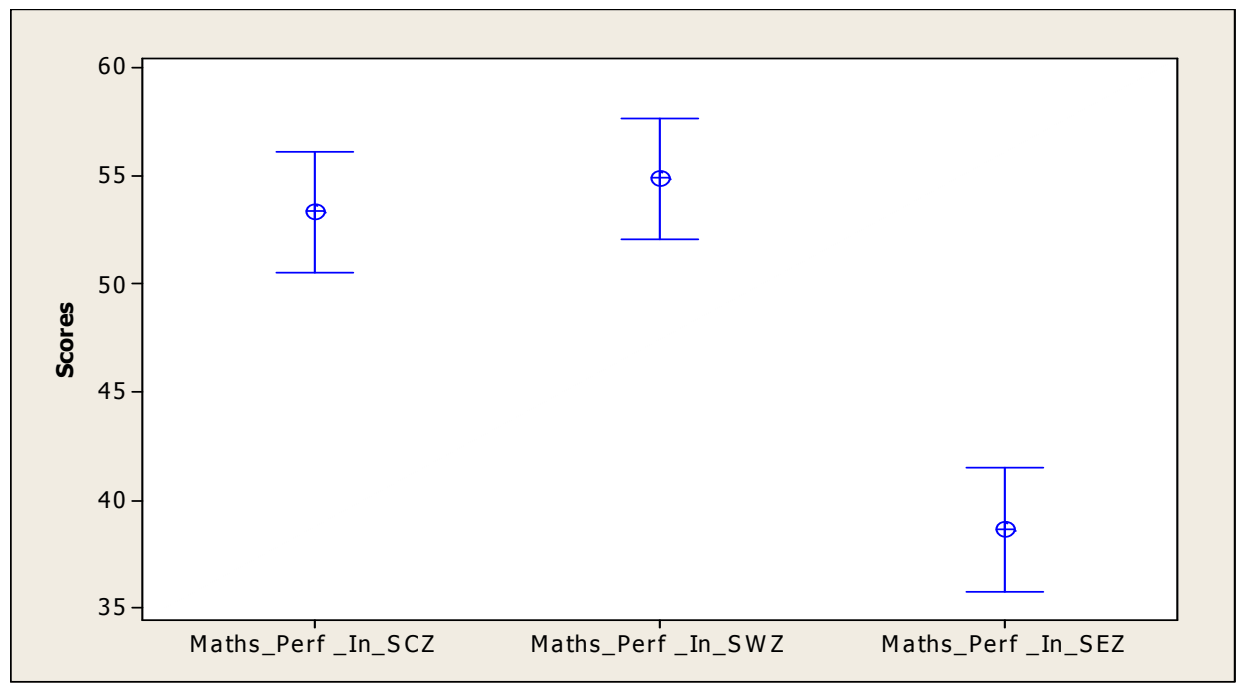

Figure 3: Mean Scores of performance in Mathematics by study subjects in the three zones of Sokoto State

The result of grades in performance of Mathematics by study subjects is presented in figure 4 :

There were $41.7 \%$ subjects in SEZ compared to $28.9 \%$ subjects in SCZ and $32.9 \%$ subjects in SWZ scoring below satisfactory level ranging from fair and poor performance in Mathematics. For satisfactory performance the study observed $48.2 \%$ subjects of SCZ,
$46.8 \%$ subjects in SWZ compared to $45.2 \%$ subjects in SEZ. The study also showed good performance in $14.5 \%$ SCZ subjects, $12.7 \%$ SWZ subjects compared to $10.7 \%$ subjects. Eight point four percent subjects in SCZ, $7.6 \%$ subjects in SWZ compared to $4.8 \%$ subjects in SEZ had an excellent performance in English language.

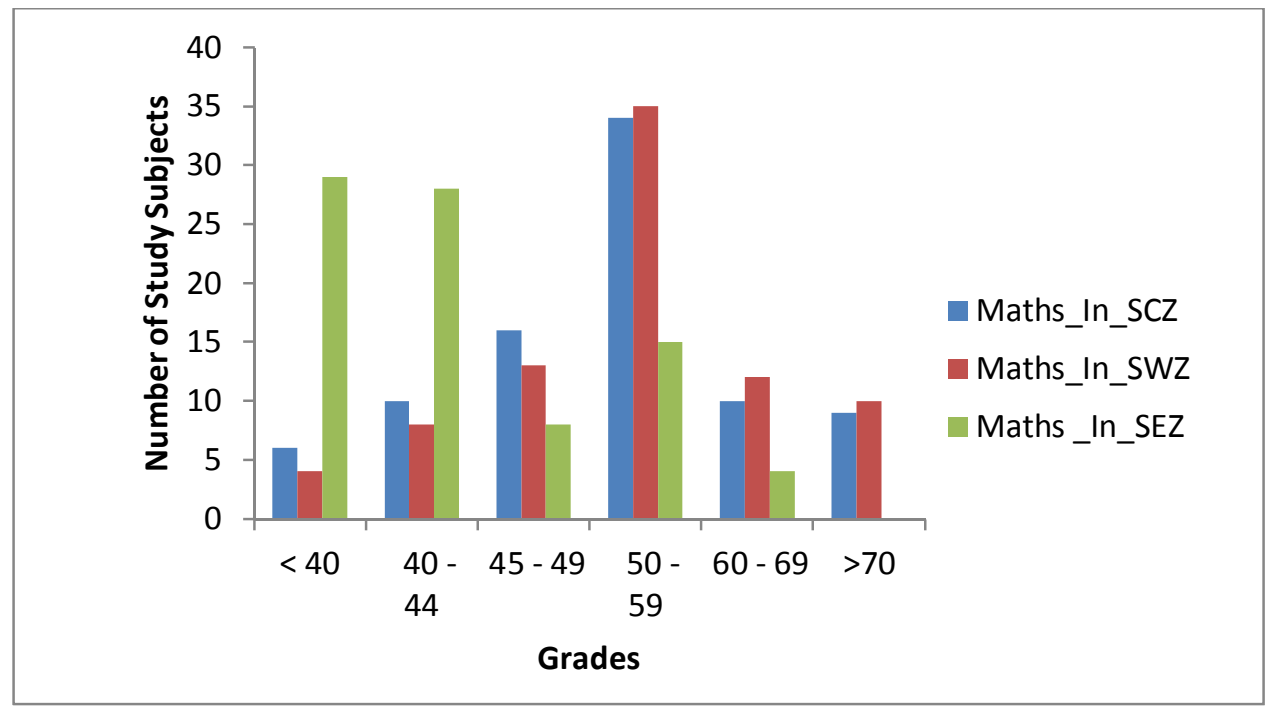

Figure 2: Grades of performance in Mathematics by study subjects in the zones of Sokoto State

\section{DISCUSSION}

It is evident from the results that iodine deficiency can affect the academic performance of girls. Thirty five percent of the subjects with mild to moderate iodine including some subjects with marginal iodine sufficiency across the three regions had a poor performance. This study differed from the report on Pakistani iodine deficient schools girls which showed poor academic performance in almost $20 \%$ of the student (Robina et al., 2014). The study is almost similar to the findings of Bhowal et al., (2014) who reported $37.56 \%$ iodine deficient subjects of Indian school children with poor academic achievement. The finding of this study is comparable with a study in Tanzania that revealed a link between baseline iodine deficiencies and decreased female secondary school academic performance. The study is similar to the 
findings of Bath et al., (2013) who reported that even in developed countries, marginal iodine sufficiency may lead to intellectual compromise. A meta-analysis of studies in Spain and Australia in relating iodine deficiency to cognitive development suggested that iodine deficiency alone caused an average loss of 13.5 intelligence quotient (IQ) points in affected subjects (Bleichrodt and Born, 1994). The economic, social and developmental implication of this is that people in iodinedeficient communities are typically less educated and less economically productive. Correction of the deficiency has resulted in dramatic improvement in school performance, agricultural output, and per capita income.

In Jaen province, Spain, school children with urinary iodine concentrations below $100 \mu \mathrm{g} / \mathrm{L}$ were reported to have lower IQ scores: 96.4 versus 99.0 in school children with urinary iodine concentrations greater than $100 \mu \mathrm{g} / \mathrm{L}$ (Santiago-Fernandez et al., 2004). The children grew up in a region considered to be iodine sufficient (median urinary iodine concentration $108 \mu \mathrm{g} / \mathrm{L}$ ), and therefore the results reflect the effects of fetal rather than childhood iodine insufficiency (Zimmermann, 2005). In Australia, children born to mothers with urinary iodine concentrations during pregnancy of less than $150 \mathrm{mcg} / \mathrm{L}$ compared with $\geq 150 \mathrm{mcg} / \mathrm{L}$ had reductions in spelling, grammar, and English-literacy standardized test scores at age nine years (Hynes et al., 2013). Intellectual disability resulting from the effects of iodine deficiency on the central nervous system during foetal development is not reversible

\section{CONCLUSION}

Inadequate iodine status in the study subjects is associated with decrease in their academic performance.

\section{RECOMMENDATION}

Adequate iodine intake should continue to be encouraged in the general population more especially in the secondary schools girls, most of whom are at verge of becoming mothers of children who would be enrolled in schools

\section{REFERENCES}

Andersson M, Takkouche B and Egli I. (2005). Current global iodine status and progress over the last decade towards the elimination of iodine deficiency. Bull World Health Organ; 83:518.

Asuai NC. and Adeleye BA. (2013). Impact of Peer Assessment on Performance in Mathematics among Senior Secondary School Students in Delta State,
Nigeria: Journal of Emerging Trends in Educational Research and Policy Studies (JETERAPS) 4(5): 719725.

Bath SC, Steer CD and Golding J. (2013). Effect of inadequate iodine status in UK pregnant women on cognitive outcomes in their children: results from the Avon Longitudinal Study of Parents and Children (ALSPAC). Lancet; 382:331.

Bleichrodt N and Born MP (1994). A metaanalysis of research on iodine and its relationship to cognitive development. In: The damaged brain of iodine deficiency, Stanbury JB (Ed), Cognizant Communication Corporation, New York. p.195.

Bhowal K, Mukherjee I. and Chaudhur D. (2014). Association of iodine status with IQ level and academic achievement of rural primary school children in West Bengal, India: Indian Journal of Community Health; 26 (2):Pp $217-220$.

Hynes KL, Otahal P, Hay I. and Burgess JR. (2013). Mild iodine deficiency during pregnancy is associated with reduced educational outcomes in the offspring: 9-year follow-up of the gestational iodine cohort. $J$ ClinEndocrinolMetab,98:1954.

Hetzel BS. (2005). lodine deficiency disorders (IDD) and their eradication. Lancet; 2(8359): 1126-1129.

IDD-Newsletter. (2010). Report on Situation Assessment of Production, Marketing and Consumption of lodized Salt in Nigeria.

Olatunde AA. (2012). Why Candidates Fail in Public Examination: Being a Paper presented to the Federal Ministry of Education National Stake holders consultative Meeting on Improving Performance in public Examination.

Robina M, Musarat Ramzan and Anwar B. (2014). Effects Of lodine Deficiency Goiter On Academic Performance Of Girls:Biomedica ;1 (30) 40 - 43.

Santiago-Fernandez $\mathrm{P}$, Torres-Barahona $\mathrm{R}$ and MuelaMartínez JA (2004). Intelligence quotient and iodine intake: a cross-sectional study in children. $J$ Clin Endocrinol Metab; 89:3851.

Salako RJ, Adegoke BO. and Ogundipe LO. (2017). Performance Appraisal of NECO, WAEC and SSCE: An Empirical Evidence from Mathematics and Physics; International Journal of Innovative Social and Science Education Research; 5(3):1 - 10.

WHO, UNICEF, ICCIDD. (2001). Assessment of iodine deficiency disorders and monitoring their elimination.Geneva, World Health Organization, (WHO/NHD/01.1).

White H. and Sabarwal S. (2014). Quasi-experimental Design and Methods, Methodological Briefs: Impact Evaluation; 8, UNICEF Office of Research, Florence.

Zimmermann MB. (2007). The adverse effects of mild-tomoderate iodine deficiency during pregnancy and childhood: a review. Thyroid; 17(9): 829-835.

Zimmermann MB. (2009). lodine deficiency.Endocr Rev; 30(4): 376-408. 